\title{
MOLECULAR AND GENOTYPES IDENTIFICATION OF C. ALBICANS ISOLATED FROM CHILDREN WITH DIARREA IN DIYALA PROVINCE-IRAQ
}

\section{ALI R. HAMEED ${ }^{1}$, LUMA T. AHMED ${ }^{2} \&$ SABAH M. ALI ${ }^{3}$}

${ }^{1,2}$ Research Scholar, Department of Microbiology, College of Medicine, University of Diyala, Iraq

${ }^{3}$ Research Scholar, Department of Pediatrics, College of Medicine, University of Diyala, Iraq

\section{ABSTRACT}

BACKGROUND

Candida species, one of the most fungi, which isolated from clinical samples that cause many problems to humans, frequently isolated from stools of children with diarrhea.

\section{OBJECTIVE}

The aim of the study is, Isolation and identification of Candida spp. and genotype of Candida albicans infection, among children with diarrhea using conventional methods and PCR, and study distribution of Candida spp. and explore the effect of some relevant factors, in Diyala -province.

\section{MATERIALS AND METHODS}

A total of 100 children under three years, suffering from diarrhea were included in this study, over a two month period (from $1^{\text {st }}$ October 2016 to $3^{\text {rd }}$ November 2016), in AL-Batool Teaching Hospital. The stool was collected for microscope stool examination, Stool culture on SDA, germ tube test, Chlamydospore formation test, CHROM agar Candida (CAC) and PCR techniques.

\section{RESULTS}

The results showed that, infection rate by Candida spp., among the patients were (64\%), (37.5\%) of the total isolates were identified Candida as C. albicans, (62\%) isolates was identified as non-albicans., of which (21.9\%) isolates were C. glabrata, (17.2\%) isolate C. parapsilosis, (12.5\%) isolates was C. krusei (10.9\%) isolates was C. tropicalis. PCR amplification $25 \mathrm{~S}$ rRNA gene show three genotypes $(A, B, C)$, results showed. (83.3\%) for genotype A, (8.3\%) for each genotype $B$ and genotype $C$. the results showed, there are significantly $(P<0.05)$ higher Candida infection rate among children with previous antibiotic use and without previous antibiotic, actuality (73.1\%), The higher infection rate among children consuming non-sterilization water and children consuming sterilization water, actuality 38(73.1\%), Although, insignificant(P>0.05), the results showed Candida infection rate higher in male patients compared to female patients $(66.7 \%$ vs. $60.5 \%)$ and high Candida infection rate in ( $\geq 2)$ months patients compared other age groups, actuality $7(77.8 \%)$

\section{CONCLUSIONS}

C. albicans is the most common isolated from among the total Candida species, and Candida glabrata was the most frequent non-albicans species. C. albicans genotype A, is the most frequent genotype in patients, followed by genotype $B$ and $C$ with the equal rate.

KEYWORDS: Candida Spp., Candida. Albicans Genotype \& Diarrhea in Children 
Received: Sep 25, 2017; Accepted: Oct 15, 2017; Published: Oct 26, 2017; Paper Id: IJBTRDEC20171

\section{INTRODUCTION}

Candida species constitute part of the normal microbiota of the human mucosal, oral cavity, vagina, and gastrointestinal tract. Several species, including Candida albicans, C. dublinensis, C. glabrata, C. guilliermondii, C. Lusitaniae, C. parapsilosis and C. tropicalis, can be found as part of the normal human commensal flora, especially in all sections of the gastrointestinal tract [1] [2]. In normal, healthy person, there is a balance between Candida species, as a normal flora and the normal defense mechanism of the body [3], which will cause opportunistic infection in the presence of any of the predisposing factors like; diabetes mellitus, malnutrition [4], humidity, burn, HIV infection [5], renal failure, endocrine disturbance [6], cancer, indiscriminate usage of antibiotics [7], glucocorticoids and cytotoxic drugs [5]. However, in response to improve or disturbance in the sponsor security systems in the gut, like the intestinal microbiota, gut-associated disease fighting capability, and the mucosal hurdle, Candida spp., can convert from safe commercials into pathogens or disturbance in the host defense systems, in the gastrointestinal, including the intestinal microbiota, gut-associated immune system, and the mucosal barrier, Candida spp., can convert from harmless commensals into pathogens [8]. Colonization of the gastrointestinal and genitourinary tract, may occur during birth directly from the birth canal [9], at some time during infancy or perhaps later in life, in which, the source may be environmental like polluted fresh and marine water [10], soil, air [11], plant [3], contamination of bedding, hospital wards and wash basins, or could be of human source (mucous membrane or gastrointestinal tract) [12]. Candida albicans is the most common Candida spp., isolated from human stool. Nevertheless, several reports have suggested that, it may cause diarrhea, as it has also been proposed as a cause of antibiotic-associated diarrhea (AAD), in infants. In recent years, the incidence of Candida spp. infections has increased. It has also been shown to be $C$. albicans that also causes diarrhea [13]. Although, not commonly suspected clinically, such pathogenic yeast/yeast-like fungi can increase the severity of diarrhea, causing severe dehydration, malnutrition, and mortality [13].

\section{MATERIAL AND METHODS}

\section{SAMPLE COLLECTION}

Hundred stool samples were collected from children suffering from diarrhea, during a two month period (from $2^{\text {nd }}$ October 2016 to $3^{\text {rd }}$ December 2016). Less three years attending in AL-Batool Teaching Hospital in Baquba.

\section{CULTURE MEDIA}

All the collected samples were inoculated directly, on Sabouraud dextrose agar (SDA) containing Chloramphenicol. The inoculated were kept for incubation, for $48 \mathrm{hrs}$, for Lactophenol cotton blue stain examination of Candida spp.

\section{PHENOTYPE IDENTIFICATION OF CANDIDA SPP}

\section{Germ tube (GT) test}

Rapid diagnostic differentiates C. albicans from other species. The inoculums of yeast cells obtained from an isolated colony were suspended in the $0.5 \mathrm{ml}$ of serum, were incubated at $37^{\circ} \mathrm{C}$ for $3 \mathrm{hrs}$. Microscopical examination of the germ tubes, presentation [14]. 
Drops of CAM were added to the slide and left until becoming dry, a part of four days old colonization has been grown up on SDA; was streaked on the slide, later drops of distilled water were added on the filter paper; to keep it humid and moist. The plate was incubated at $25-35^{\circ} \mathrm{C}$ for $4-6$ days. After an incubation period; a drop of lactophenol blue stain was added to the slide, covered with examined under a microscope (40x) to recognize chlamydospores. [15].

\section{CHROM Agar Candida}

Candida was resuscitated by inoculating a loop full of culture from Sabouraud Dextrose Agar into CHROM agar media by streaking a loop full of culture and incubated at $37^{\circ}$ for 72 hours. After $72-96$ hours of incubation, the Candida colonies were initially identified by colonial color when compared with standard color photographs supplied by the manufacturer and also presented [16].

\section{IDENTIFICATION GENOTYPE OF CANDIDA ALBICANS}

\section{DNA Extraction}

Isolates of the Candida albicans were suspended in $3 \mathrm{ml}$ of (YPD) for $48 \mathrm{hrs}$., at 37C. Genomic DNA was extracted using Wizard Genomic DNA purification kit (Promega, USA). Extracted DNA was transferred to a sterile $1.5 \mathrm{ml}$ Microcentrifuge tube and stored at $-20{ }^{\circ} \mathrm{C}$.

\section{Primers}

The primer pairs used for detection the 25S rRNA were CA-INT-L (5-ATA AGG GAA GTC GGC AAA ATA CCG TAA-3) and CAINT-R (5-CCT TGG CTG TGG TTT CGC TAG ATA GTA GAT-3) as described by McCullough13, primers were synthesized by (Bioneer Co., USA). Amplification reactions were performed in the $25 \mu 1$ final volume containing 12.5 master mix (Promega, USA), $1.25 \mu \mathrm{l}$ (25 pmol) each of the primers and $5 \mu$ DNA template and complete the volume of PCR grade water. The mixtures reaction was subjected to the following thermal cycling parameters $94 \mathrm{oC}$ for 3 min. Followed by 30 cycles of $94 \mathrm{oC}$ for $1 \mathrm{~min}, 55 \mathrm{oC}$ for $1 \mathrm{~min}, 72 \mathrm{oC}$ for $2.5 \mathrm{~min}$ and a final extension at $72 \mathrm{oC}$ for $10 \mathrm{~min}$ following the last cycle. All reaction products by electrophoresis on 1.5\% agarose-diamond nucleic acid gel in $1 \mathrm{X}$ TBE buffer at $100 \mathrm{~V}$ for $1 \mathrm{hrs}$. And visualized in Gel documentation system. Molecular grade water was included randomly as negative controls and C. albicans as a reference in the study.

\section{RESULTS}

\section{Culture Media}

Morphological culture on Sabouraud dextrose agar SDA medium, the colonies of C. albicans colonies on sabouraud dextrose agar were white to creamy, round, soft, and smooth to wrinkled, with a characteristic yeast odor [Figure 1]. Lactophenol cotton blue stain examination of $C$. albicans isolates showed spherical to oval cells, with a presence of budding and was much larger than bacterial cells [Figure 2]. The results of specimen cultures of SDA results showed that, 64 isolates were obtained from 100 samples. 


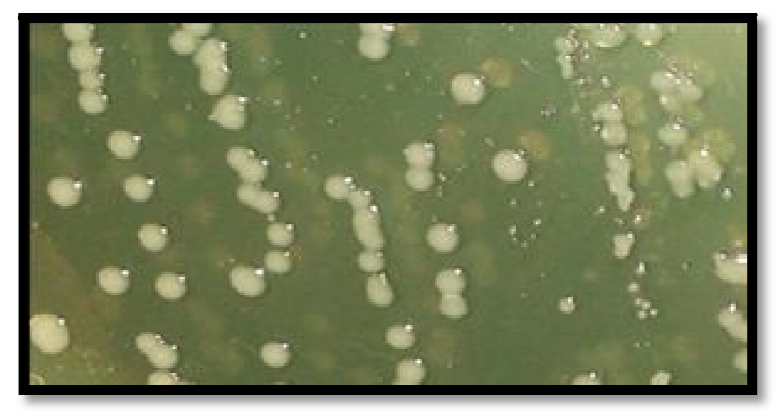

Figure 1: Colonies of Candida Spp. Cultured on SDA at $37^{\circ} \mathrm{c}$ for $48 \mathrm{Hrs}(40 \mathrm{X})$

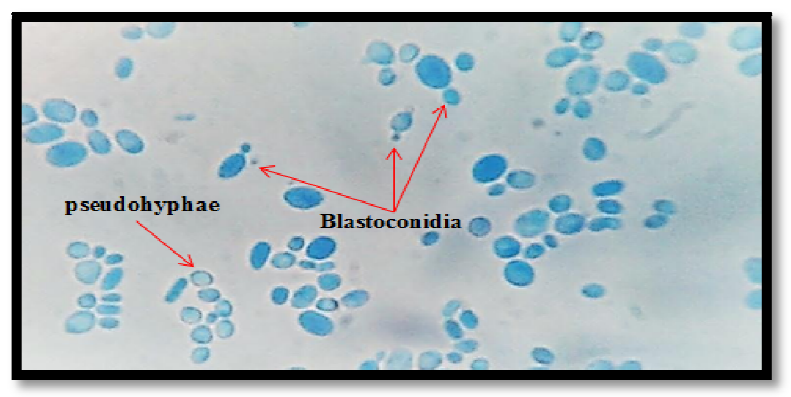

Figure 2: Blastoconidia and Pseudohyphae of the C. Albicans Stained With Lactophenol Cotton Blue (40X)

\section{Phenotype Identification of Candida Spp}

Germ tube (GT) formation was tested, and this test showed that, 24 isolates were positive that the formation of germ tube, which was seen as a long tube-like projections extending from the yeast cells [Figure 3]. Chlamydospore is another test identification character, for identifying C.albicans than other species. They were spherical, thick-walled, and usually produced by suppurating cells, that occur along pseudohyphae or at the tip of hyphae. Pseudohyphae and hyphae with clusters of blastospores are also produced, on this agar, [Figure 4]. The colour of colonies on CHROM agar Candida was similar, as given by the manufacturer, i. e. green colonies of C. albicans. Blue colonies of C. tropicalis, Purple- Pink colored colonies of C. krusei, C. glabrata produced cream to white and C parapsilosis produced pinkish to white,[Figure 5]. The present study shows, difference between Candida spp., 24 (37.5\%) of the total isolated were identified Candida, as C. albicans, $40(62 \%)$ isolates were identified as non-albicans., of which $14(21.9 \%)$ isolates were C. glabrata, 11 (17.2\%) isolate C. parapsilosis and 8 (12.5\%) isolates were C. krusei 7 (10.9\%) isolates were C. tropicalis.

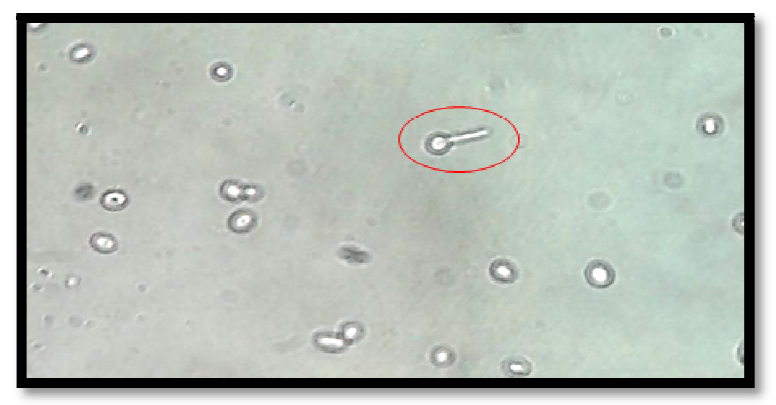

Figure 3: Germ Tube Formation by C. Albicans (40X) 


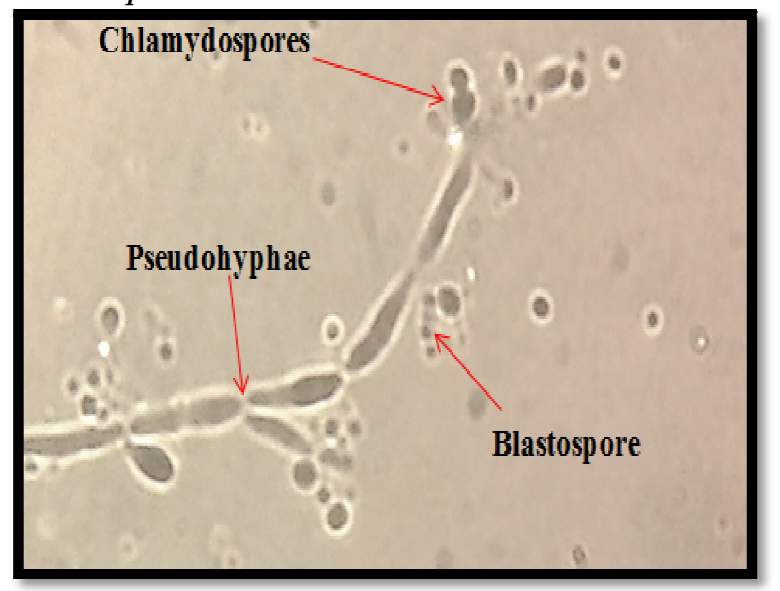

Figure 4: Pseudohyphae, Blastospore and Chlamydospores of $C$. Albicans Cultured on CMA at $30{ }^{\circ} \mathrm{C}(40 \mathrm{X})$

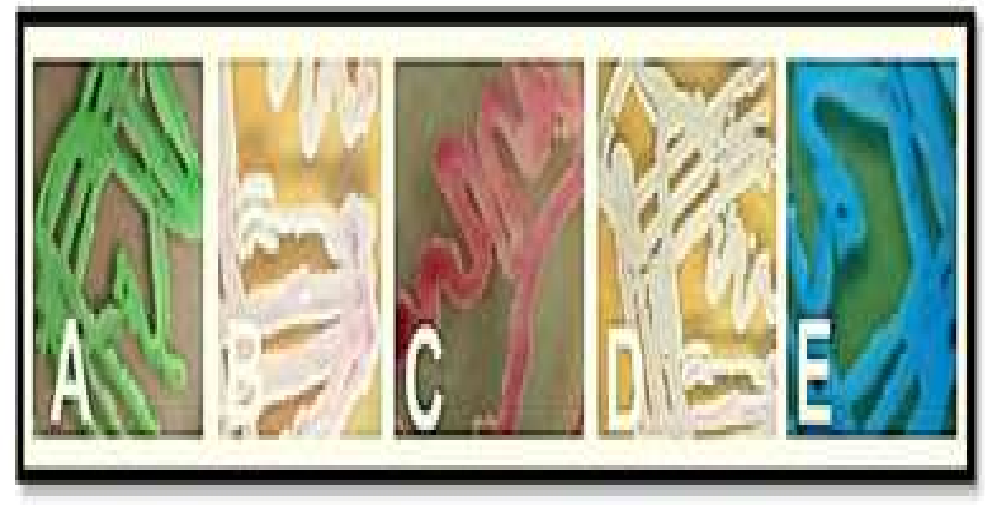

Figure 5: colonies of Candida spp A. C. albicans B. c parapsilosis C, C.krusei:D.C. glabrata and E.C. tropicalis cultured on CHROM agar candida at $37 \mathrm{C}$ for 48 hrs Appeared different colors

\section{Identification Genotype of Candida Albicans}

Polymerase chain reaction method, using a primer pair designed to span a V3 region in chromosome R, that involve the site of the transposable group I intron of the 25S rRNA gene. Polymerase Chain Reaction amplification, shows three genotypes (A, B, C), results showed single amplification product size (450bp) for $20(83.3 \%)$ isolate, and thus, categorize isolates as genotype $\mathrm{A}$ of the $C$. albicans; single amplification product size ( $840 \mathrm{bp})$ for $2(8.3 \%)$ isolates and thus, categorize isolates as genotype B C. albicans and amplification providing two sizes (450 and $840 \mathrm{bp}$ ) for 2 (8.3\%) and this categorize isolate as genotype $\mathrm{C}$ of the C. albicans[ Figure 6]. 


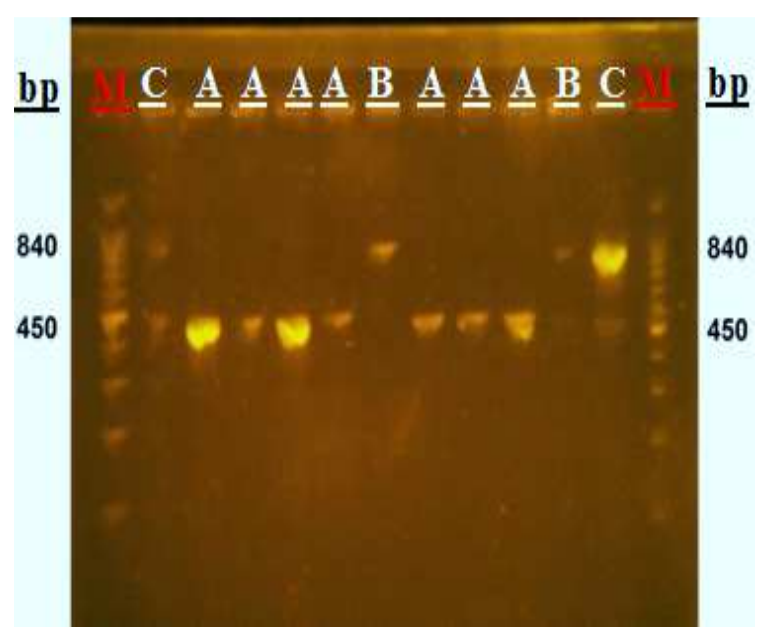

Figure 6: Agarose Gel Electrophoresis of the Candida Albicans Genotype, Stained With Diamond Nucleic Acid Lane M: Molecular Marker (100bp), Lanes A:

Genotype A; Lanes B: Genotype B: Lanes C: Genotype C.

In this study, the results showed there are significant $(\mathrm{P}<0.05)$ higher Candida infection rate, among children with previous antibiotic use and without previous antibiotic, actuality $38(73.1 \%)$ as shown in [Table 1]

Table 1: Candida Infection Rate among Patients According To Previous Antibiotic Use

\begin{tabular}{|l|l|c|c|c|c|c|}
\hline \multicolumn{2}{|c|}{$\begin{array}{c}\text { Previous } \\
\text { Antibiotic Use }\end{array}$} & \multirow{2}{*}{ Total Samples } & \multicolumn{2}{c|}{ Candidiasis } & \multicolumn{2}{c|}{$\begin{array}{c}\text { Comparison of } \\
\text { Significant }\end{array}$} \\
\cline { 4 - 7 } Yes & No. & 52 & 38 & 14 & P-value & Sig \\
\cline { 2 - 7 } & $\%$ & $100.00 \%$ & $73.10 \%$ & $26.90 \%$ & & \\
\hline \multirow{2}{*}{ No } & No. & 48 & 26 & 12 & 0.045 & sig. \\
\cline { 2 - 5 } & $\%$ & $100.00 \%$ & $54.20 \%$ & $45.80 \%$ & & $(\mathrm{P}<0.05)$ \\
\hline \multirow{2}{*}{ Total } & No. & 100 & 64 & 36 & & \\
\cline { 2 - 5 } & $\%$ & $100.00 \%$ & $64.00 \%$ & $36.00 \%$ & & \\
\hline
\end{tabular}

The highest infection rate among children consuming non-sterilization, water and children consuming sterilized water, actuality $38(73.1 \%)$ as shown in [Table 2]

Table 2: Candida Infection Rate among Patients According to the Water Sterilization

\begin{tabular}{|c|c|c|c|c|c|c|}
\hline \multirow{2}{*}{\multicolumn{2}{|c|}{$\begin{array}{c}\text { Water } \\
\text { Sterilization }\end{array}$}} & \multirow{3}{*}{$\begin{array}{c}\begin{array}{c}\text { Total } \\
\text { Samples }\end{array} \\
52\end{array}$} & \multicolumn{2}{|c|}{ Candidiasis } & \multirow{2}{*}{\multicolumn{2}{|c|}{$\begin{array}{l}\text { Comparison of } \\
\text { Significant }\end{array}$}} \\
\hline & & & \multirow{2}{*}{$\begin{array}{c}\text { (+ve) } \\
38\end{array}$} & \multirow{2}{*}{$\begin{array}{c}(-\mathbf{e}) \\
14 \\
\end{array}$} & & \\
\hline \multirow{2}{*}{ No } & No. & & & & P-value & Sig \\
\hline & $\%$ & $100.00 \%$ & $73.1 \%$ & $26.9 \%$ & & \\
\hline \multirow{2}{*}{ Yes } & No. & 48 & 26 & 22 & 0.045 & Sig. \\
\hline & $\%$ & $100.00 \%$ & 54.2 & $45.8 \%$ & & $(\mathrm{P}<0.05)$ \\
\hline \multirow{2}{*}{ Total } & No. & 100 & 64 & 36 & & \\
\hline & $\%$ & $100.00 \%$ & $64.00 \%$ & $36.00 \%$ & & \\
\hline
\end{tabular}

Although, insignificant $(\mathrm{P}>0.05)$, the results showed a Candida infection rate higher in male patients compared to female patients $(66.7 \%$ vs. $60.5 \%)$ as shown in [Table 3], the high Candida infection rate in $(\geq 2)$ months patients compared 
other age groups, actuality $7(77.8 \%)$ as shown in [Table 4$]$

Table 3: Candida Infection Rate among Patients According to the Gender

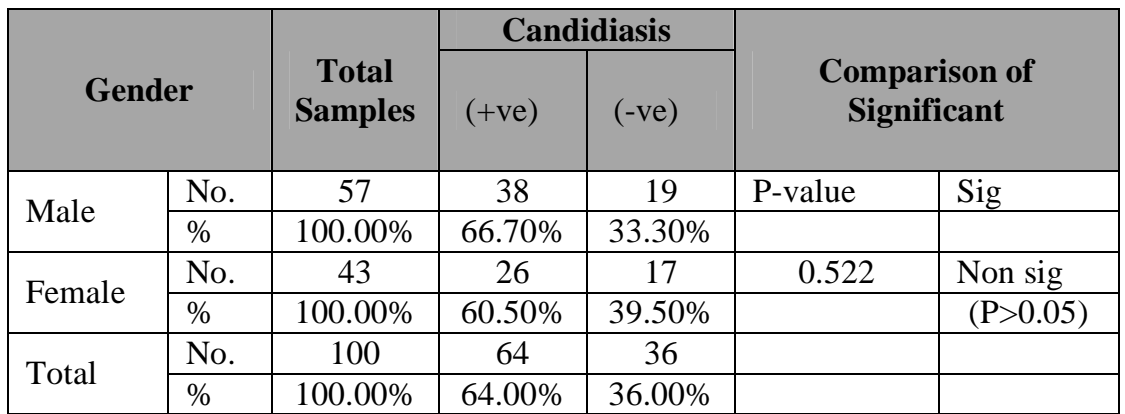

Table 4: Candida Infection Rate among Patients According to the Age

\begin{tabular}{|c|c|c|c|c|c|c|}
\hline \multirow{2}{*}{\multicolumn{2}{|c|}{ Age(Month) }} & \multirow{3}{*}{$\begin{array}{c}\begin{array}{c}\text { Total } \\
\text { Samples }\end{array} \\
9\end{array}$} & \multicolumn{2}{|c|}{ Candidiasis } & \multicolumn{2}{|c|}{ Comparison of Significant } \\
\hline & & & \multirow{2}{*}{$\frac{(+\mathrm{Ve})}{7}$} & \multirow{2}{*}{$\frac{(-\mathbf{V e})}{2}$} & \multirow[t]{2}{*}{ P-Value } & \multirow[t]{2}{*}{ Sig } \\
\hline \multirow{2}{*}{$\geq 2$} & No. & & & & & \\
\hline & $\%$ & $100 \%$ & $77.80 \%$ & $22.20 \%$ & & \\
\hline \multirow{2}{*}{$3-5$} & No. & 27 & 14 & 13 & 0.585 & Non sig. \\
\hline & $\%$ & $100 \%$ & $51.90 \%$ & $48.10 \%$ & & $(\mathrm{P}>0.05)$ \\
\hline \multirow{2}{*}{$6-11$} & No. & 40 & 27 & 13 & & \\
\hline & $\%$ & $100 \%$ & $67.50 \%$ & $32.50 \%$ & & \\
\hline \multirow{2}{*}{$12-23$} & No. & 14 & 9 & 5 & & \\
\hline & $\%$ & $100 \%$ & $14.30 \%$ & $35.70 \%$ & & \\
\hline \multirow{2}{*}{$24-36$} & No. & 10 & 7 & 3 & & \\
\hline & $\%$ & $100 \%$ & $70.00 \%$ & $30.00 \%$ & & \\
\hline \multirow[b]{2}{*}{ Total } & No. & 100 & 64 & 36 & & \\
\hline & $\%$ & $100.00 \%$ & $64.00 \%$ & $36.00 \%$ & & \\
\hline
\end{tabular}

\section{DISCUSSIONS}

This study considers as the first report of genotypic analysis of Candida albicans, isolated from stools of children with diarrhea in Iraq. The results of this study are agreements with Intesare and Ahmed, that the fungal organism isolated most frequently was Candida non albican isolated (62.5\%), followed by Candida albican (37.5\%) Isolated was identified as non-albicans spp., of which (34.4\%) isolated was C. tropicalis and (9.4\%) of remaining isolates were C. kruzei, C. globrata and $C$. parapsilosis[17]. The result showed that, $C$. albicans the most common isolate from clinical samples and these agree with [18] [19] [20]. In Salah Alden, Ashraf found that, the total rate of Candida albican infection was (38\%) of 508 examined stool specimens during 2007 at health centers in the Dour town [21]. In Kirkuk province, found that the total rate of C. albican infection was (25\%) of 200 examined stool specimens, during 2003 at the Pediatric Hospital in Kirkuk [22]. In Najaf governorate, Haydar et al. (2013) showed that, 21 (95.45\%) isolates belonged to the genotype A and 1 (4.54\%) isolates belonged to the genotype $\mathrm{B}$ of the $C$ albicans. [23]. The results also agree with previous studies showed genotype A of the $C$ albicans, predominant in clinical samples, while genotype B, less frequency and this very close to previous studies [24] [25]. In China, it was found that, the rate of genotype A, B, and $C$ of the $C$. albicans from children with early childhood, caries and caries-free children were (61.2\%), (15.5\%) and (23.3\%) [26]. In Northern Ireland, it was found that, rate of genotype A 
(71.5\%); B (9.5);C (9.5\%) and D (9.5\%), were obtained from the blood cultures of patients, with blood borne candidates attending the Belfast City Hospital. In addition, it was found that, the rate of genotype A (66.7\%); B (16.7\%); C (11.1\%) and $\mathrm{D}(5.1 \%)$, were obtained from the following regions (throat, groin, rectum, bronchial washings, sputum, catheter urine and endotracheal tube bio film), attending Belfast City Hospital [27].

\section{REFERENCES}

1. Moran, G., Sullivan, D., \& Coleman, D. (2012). An Introduction to the Medically Important Candida Species. Candida and Candidiasis, Second Edition, 11-25.

2. Netea, M. G., Brown, G. D., Kullberg, B. J., \& Gow, N. A. (2008). An integrated model of the recognition of Candida albicans by the innate immune system. Nature Reviews. Microbiology

3. Ferrer, J. (2000). Vaginal candidosis: epidemiological and etiological factors.

4. Conlon, C. P., \& Snydman, D. R. (2000). Mosby's Color atlas and text of infectious diseases. Edinburgh: Mosby

5. Roitte, I., Brostoff, J., \& Male, D. (1998) Immunity to bacteria and fungiImmunology (5th ed) Mosby

6. Guggenheimer, J., Moore, P. A., Rossie, K., Myers, D., Mongelluzzo, M. B., Block, H. M., Orchard, T. (2000). Insulin-dependent diabetes mellitus and oral soft tissue pathologies. II. Prevalence and characteristics of Candida and candidal lesions. Oral Surgery, Oral Medicine, Oral Pathology, Oral Radiology, and Endodontology, 89(5), 570-576

7. Law, D. K., Dudrick, S. I., \& Abdou, N. I. (1974). The Effect of Dietary Protein Depletion on Immunocompetence. Annals of Surgery, 179(2), 168-173.

8. Walker, L. A., Maccallum, D. M., Bertram, G., Gow, N. A., Odds, F. C., \& Brown, A. J. (2009). Genome-wide analysis of candida albicans gene expression patterns during infection of the mammalian kidney. Fungal Genetics and Biology: FG \& B, 46(2).

9. Al-dooray, Y. (1975). The epidemiology of human mycotic diseases.

10. Valdes-collazol L. and Yarrow (1987). Survival of Candida albicans in tropical Marine and fresh water.

11. Meyer, S. A. and Alhearn, D. G.\&Yarrow, D.(1984) Candida Berkhout. The yeast: Taxonomic study, 4th. Ed. Edited by Kurtzman C. P. and FellJ. W. Amsterdam, Elsevier Science Publishers. In press. Cited by: medicalmycology.

12. Harriott, M. M., \& Noverr, M. C. (2010). Ability of Candida albicans mutants to induce Staphylococcus aureus vancomycin resistance during polymicrobial biofilm formation. Antimicrobial agents and chemotherapy, 54(9), 3746-3755.

13. Krause, R., Krejs, G. J., Wenisch, C., \& Reisinger, E. C. (2003). Elevated Fecal Candida Counts in Patients with AntibioticAssociated Diarrhea: Role of Soluble Fecal Substances

14. Forbes, B. E., Sahm, D. F. and Weissfeld, A. S. (2007). Bailey \& Scott's Diagnostic Microbiology.12 ${ }^{\text {th }}$ ed. Mosby Elsevier. Texas, USA.

15. Wickerham, L. j. and pettger, L. E.(1939). J. Top Med. Hug. 42,174,187,204, cited in Lodder, J., pp.44.

16. Mahmoudabadi, A. Z., Drucker, D. V., Mandall N; O'Brien, K. and Theaker, E.(2000) Isolation and Identification of Candida Species from the Oral Cavity Using CHROMagar Candida, Iranian Biomedical Journal,4(2-3),57-61

17. Intesar, M., J. and Ahmed, A., M. (2012). In vitro, Study of the Effect of Four Plant Aqueous Extractson the Growth of Some 
Candida Species recovered from the stool samples of infants. Kufa Journal for Nursing Sciences, 2(3), 30-40.

18. Mendiratta, DK, Rawat, V., Thamke, D., Chaturvedi, P., Chhabra, S., Narang, P. (2006). Candida colonization in preterm babies admitted to neonatal intensive care unit in the rural setting. Indian J. Med. Micro. 24(4)263-267.

19. Nneka, U. C. and Eabele, O. M. (2005). The occurance of oral thrash yeast amoung school children in Onitsha Urban, Anambra State, Nigeria. J. Med. Sci.5 (3),177-180.

20. Roilides, E., Farmaki, E., Evdoridou, J., Dotis, J., Hatziioannidis, E., Tsivitanidou, M. \& Mueller, F. M. (2004). Neonatal candidiasis: analysis of epidemiology, drug.

21. Ashraf, J., M.( 2010). Role of Candida albicans Fungi in foundation some protozoa and bacteria. Tikrit Journal of pure science, 15,(1),14-19.

22. Ali, C. I., Mahmood, A. R., Jafar, N. A., \& Khorsheed, S. (2009). Prevalence of enteropathogenic diarrhea in Children up to 2 years in Kirkuk province. Tikrit Medical Journal, 15(2), 124-131.

23. Haydar, M. A., Al-Hamadani, A., H. and Al-Muhana, A., M.(2013). Genotyping and antifungal susceptibility profile of Candida albicans isolated from neonatal thrush infections in Iraq. al-qadisiah Medical Journa,9,(15) 240-249

24. Melahat, G. and Ilknur, K. (2010). Molecular Analysis of Candida albicans Isolates from Clinical Specimens. Mycopathologia $169,261-267$

25. Mendiratta, DK, Rawat, V., Thamke, D., Chaturvedi, P., Chhabra, S., Narang, P. (2006). Candida colonization in preterm babies admitted to neonatal intensive care unit in the rural setting. Indian J. Med. Micro. 24(4)263-267.

26. Qiu, R., Li, W., Lin, Y., Yu, D., \& Zhao, W. (2015). Genotypic diversity and cariogenicity of Candida albicans from children with early childhood caries and caries-free children. BMC oral health, 15(1), 144.

27. Xu, J., Millar, B. C., Moore, J. E., McClurg, R., Walker, M. J., Evans, J. \& McMullan, R. (2002). Comparison of API20C with molecular identification of Candida spp isolated from bloodstream infections. Journal of clinical pathology, 55(10), 774-777. 
